\title{
PANDEMIA, FRATERNIDADE E FAMÍLIA: A CONVIVÊNCIA E A IMPORTÂNCIA DA MANUTENÇÃO DOS LAÇOS FAMILIARES
}

\author{
Luciana Faísca Nahas ${ }^{1}$ \\ Ana Paula de Oliveira Antunes ${ }^{2}$
}

DOI: https://doi.org/10.47306/978-65-88213-03-2.149-164

Sumário: 1 Considerações iniciais: a pandemia que impactou o planeta; 2 Distanciamento social e vulnerabilidade; 3 Direito fundamental da criança e adolescente à convivência familiar; 4 Os limites e as possibilidades do exercício do direito de convivência em tempos de pandemia; 5 A Fraternidade como vetor principiológico para relações familiares durante e após a pandemia; Referências.

\section{Considerações iniciais: a pandemia que impactou o planeta}

$\mathrm{O}$ ano de 2.020 já entrou na história, marcado por um evento que atingiu em cheio a organização social global. Por todo o planeta, bilhões de pessoas vêm sofrendo violentamente com os impactos da disseminação da pandemia de COVID - 19, doença causada pelo Coronavírus SARS-CoV-2, que apresenta nas pessoas contaminadas um quadro clínico variável entre infecções assintomáticas a quadros respiratórios graves. Segundo informações da Organização Mundial de Saúde (OMS), cerca de 80\% dos pacientes infectados pela COVID19 podem ser assintomáticos e cerca de $20 \%$ dos casos podem requerer atendimento hospitalar por apresentarem dificuldade respiratória e deste percentual, $5 \%$ se resumem aos casos mais graves, necessitando de suporte para o tratamento de insuficiência respiratória. ${ }^{3}$

Apesar de todos os esforços de pesquisadores em escala global jamais vista, ainda não se tem um mapeamento completo da origem, causa, diagnóstico e tratamento adequado da doença, e tampouco uma vacina, dificultando o controle e estancamento da epidemia que se dissemina rapidamente todos os dias, em um crescente substancial dos casos confirmados e o número de óbitos, em especial no Brasil, que já concentra aproximadamente $10 \%$ dos casos confirmados no mundo. Segundo dados atualizados até 28 de junho de 2020 comunicados pelas

\footnotetext{
${ }^{1}$ Doutora em Direito Civil/PUC-SP. Professora de Direto Civil/UNISUL; coordenadora da pós-graduação em Direito de Família e Sucessões/CESUSC. Presidente do IBDFAM/SC. Membro da Internacional Society of Family Law. Advogada.

${ }^{2}$ Especialista em Direito Processual Civil/UFSC e em Direito de Família e Sucessões/CESUSC. Professora. VicePresidente do IBDFAM/SC. Membro da Comissão Nacional de Sucessões do IBDFAM. Vice-Presidente da Comissão de Direito de Família da OAB/SC. Advogada.

${ }^{3}$ https://coronavirus.saude.gov.br/sobre-a-doenca
} 
autoridades nacionais nas últimas 24 horas, há no Brasil 1.274.974 casos confirmados e 55.961 mortes e no mundo, há cerca de 9.825 .539 casos confirmados e 495.388 mortes. $^{4}$

Diante do quadro caótico de disseminação da doença, da resistência de sobrevida do vírus, da ausência de vacina ou medicamento específico tratamento para cura, agravado pela sobrecarga de leitos em hospitais para o atendimento dos doentes o Brasil assim como muitos países, adotou diversas estratégias para o combate e prevenção à doença, em especial, o isolamento social.

Em razão disso, surgiram inúmeras questões relacionadas ao direito de convivência entre familiares que fomentam o poder jurisdicional a encontrar alternativas rápidas, mas nem sempre ponderadas, para solucioná-las. Como responder aos anseios das famílias, quando algum dos genitores encontra-se infectado pela doença? E aquele genitor que não detém a guarda de seu filho ou a sua posse física, que não tiver condições de cumprir as medidas de isolamento, seja em razão da exposição ao risco que a profissão lhe impõe, seja pelo risco de contágio pelo deslocamento diário e convivência com colegas de trabalho em grandes empresas? O que esperar daquele genitor que reside em cidade distinta ou bairro distante e necessita do transporte público, aéreo e até mesmo serviço de hotelaria para conviver com a sua prole? Aos avós que costumam conviver diariamente a auxiliar nos cuidados e educação de seus netos, é viável lhes cortar radicalmente a convivência familiar, fadando-os ao esquecimento e abandono por tempo indeterminado?

Os questionamentos são infinitos: como evitar que pais omissos se ocultem sob o manto do confinamento, para eximirem-se das suas obrigações de conviver e cuidar, sobrecarregando o outro progenitor que ficará responsável pelos cuidados diários somados às atividades escolares virtuais? Com a suspensão das aulas presenciais e implementação do ensino virtual, ou antecipação das férias escolares, como compartilhar também as responsabilidades entre os pais de zelar pela parte pedagógica, mantendo a organização da casa e conciliando muitas vezes, as atividades profissionais que passam a se desenvolver no sistema de "home office"? E quanto aos avós idosos que moram em cidades distintas e não têm acesso a celulares inteligentes, internet ou não conhecem a tecnologia necessária para manter a convivência virtual com os familiares e netos?

O presente artigo tem por objetivo apontar diretrizes para a solução dos problemas acima descritos, buscando no princípio da fraternidade fundamento jurídico para que o sistema de justiça brasileiro possa aplicar a Doutrina da Proteção Integral à criança e ao adolescente de

\footnotetext{
${ }^{4}$ https://www.who.int/docs/default-source/coronaviruse/situation-reports/20200626-covid-19-sitrep158.pdf?sfvrsn=1d1aae8a_2\&ua $=1$
} 
forma a equilibrar os direitos fundamentais à convivência familiar, e a proteção à sua saúde, física e mental. Para tanto, o presente artigo irá enfrentar os temas do distanciamento social, da vulnerabilidade de membros familiares, bem como a importância da convivência familiar, e as possibilidades de sua efetivação neste período. Por fim, buscará compreender o princípio da fraternidade como vetor de promoção de mudanças paradigmáticas, na busca da cultura da paz e do resgate da família como núcleo de proteção. O método utilizado foi o dedutivo, com pesquisa bibliográfica e análise jurisprudencial.

\section{Distanciamento social e vulnerabilidade}

No meio de tantas incertezas, há pelo menos alguma direção no que tange aos cuidados e restrições de isolamento impostas pelas autoridades mundiais, e aos cuidados básicos sanitários para que se possa evitar o contágio: lavar as mãos ou higieniza-las com frequência com álcool gel, evitar contatos, higienizar superfícies e usar a máscara quando sair de casa.

Além disso, conforme a velocidade de contágio em cada localidade, as autoridades públicas podem ampliar ou reduzir a circulação de pessoas em locais públicos e privados.

O afastamento social pode se dar por medidas mais leves, como o distanciamento
social, que se traduz na recomendação de manter a distância de 2 metros, tendo por
consequência suspensão de aglomerações, aulas e eventos; o isolamento, que consiste
em separar pessoas sintomáticas das assintomáticas; a quarentena obrigatória, com a
proibição de atividades não consideradas essenciais, e até mesmo a restrição de
trânsito mais drástica, conhecida como lockdown, em que a permanência em casa se
torna em uma obrigação, somente sendo permitido circular no espaço público com
autorização ou justificativa. Tais medidas estão sendo adotados pelos diversos países
do mundo em distintas escalas, em conformidade com as análises científicas do
crescimento do número de casos em cada local e do posicionamento político de cada
autoridade. (NAHAS; FONTANELLA, 2020, p. 56-57).

Ainda, é importante destacar que a doença causada pelo Coronavírus é agravada aos grupos de risco compostos principalmente por portadores de doenças crônicas como diabetes, doenças do coração e hipertensão, asma, gestantes e indivíduos acima de 60 anos. Embora as crianças e adolescentes não estejam incluídas no grupo de risco, são consideradas vulneráveis, merecendo maior proteção em tempos de crise pandêmica, no que se refere aos seus cuidados, exposição e convivência familiar e parental.

Neste contexto, importante distinguir risco e vulnerabilidade: a vulnerabilidade consiste em um grau de suscetibilidade para adquirir problemas de saúde, se distinguindo do risco, que é a probabilidade ou chance da pessoa adoecer em razão de um diagnóstico grave de saúde. Essa condição de vulnerabilidade, permanente ou temporária se justifica por inúmeros fatores, 
como etário, psíquico, legislativo, físico dentre outros, como no caso da criança e adolescente, que na condição de sujeitos em desenvolvimento merecem proteção especial.

Sob a ameaça constante da contaminação iminente, as famílias se isolaram em pequenos núcleos para proteção de seus membros. Se por um lado as medidas de distanciamento social são recomendadas para reduzir a velocidade de propagação do vírus, por outro inviabilizaram muitas vezes, a convivência parental entre as crianças e adolescentes com sua família, modificando drasticamente o direito de convivência parental e familiar.

A crise gerada pelo Coronavírus foi vetor de agravamento de situações em que já havia polêmicas relativas à guarda e convivência de filhos; pais conflituosos acentuaram entraves para o desenvolvimento das relações familiares de forma saudável, frente às inúmeras variáveis que incluem desde a restrição de contato físico, como também as limitações de contato telepresencial ou telefônico, ocasionados por uma gama interminável de novas conjunturas. E estes conflitos ultrapassam os limites das relações paterno-filiais, atingindo as relações das crianças com sus avós, tios, primos. No entanto, não se pode perder de vista o direito à convivência familiar, que deve servir de norte para solução jurídica.

\section{Direito fundamental da criança e adolescente à convivência familiar}

A imposição de medidas de distanciamento ou isolamento social não deve, via de regra, ser suficiente para impedir o contato dos pais com filhos ou justificar mudanças drásticas de guarda ou convivência, já que o direito à convivência familiar é direito fundamental garantido no artigo 227 da Constituição Federal, que o impõe com absoluta e total prioridade o dever à família, à sociedade e ao Estado. A garantia da convivência familiar é essencial para o desenvolvimento sadio da criança, e a formação de vínculos afetivos, como destacam prof. Josiane Petry Veronese e Helen Sanches:

Na esteira da Doutrina da Proteção Integral e aos princípios previstos na Convenção Internacional sobre os Direitos da Criança, a Constituição Federal em vigor estabeleceu como direito fundamental de crianças e adolescentes a convivência familiar e comunitária.

Conclamando que 'família é a base da sociedade' (art. 226, CF) e que cabe a ela, juntamente com a comunidade e o Estado, assegurar à criança e ao adolescente o exercício de direitos fundamentais (art. 227, CF), o legislador brasileiro procurou ressaltar a importância da vida em família como ambiente natural para o desenvolvimento daqueles que ainda não atingiram a vida adulta, valorizando a convivência, na família natural ou substituta.

Essa compreensão acerca da imprescindível necessidade de constituição de vínculos afetivos, para que a criança e o adolescente desenvolvam-se de forma plena, encontra como fonte a Declaração dos Direitos da Criança da Organização das Nações Unidas (ONU), de 20 de novembro de 1.959. (SANCHES; VERONESE, 2017, p. 143). 
O direito de convivência foi protegido também pela Convenção sobre os Direitos da Criança de 1989 que dispõe expressamente acerca do direito da criança que esteja separada de um ou de ambos os pais de manter regulamente relações pessoais, e contato direto com ambos, a menos que isso seja contrário ao direito maior da criança. (VERONESE, 2019, p. 22) De acordo com o artigo $9^{\circ}$ da Convenção Sobre os Direitos das Crianças (o tratado de
direitos humanos mais amplamente ratificado da história da humanidade - foi
ratificado por 196 países), as crianças não devem ser separadas 'dos pais contra a
vontade dos mesmos'. Na hipótese de separação dos pais, a convenção assegura o
direito às crianças de 'manter regularmente relações pessoais e contato direto com
ambos', salvo nos casos em que isso for contrário ao melhor interesse da criança.
(VARGAS, 2020, p. 241).

$\mathrm{O}$ direito à convivência não se resume a mera visitação, ou contatos superficiais. A convivência deve garantir a formação de laços, vínculos, afetos, estando relacionada a cuidados, responsabilidades. Estar junto, acompanhar nas atividades escolares, cuidados pessoais da criança (como banho, vestimentas, higiene), estar presente em consultas médicas e odontológicas, além das atividades de lazer reservadas aos fins de semana. Como destaca Conrado Paulino da Rosa:

Ao 'com viver'[...] estabelecemos uma rotina de coexistência, de elo e não de mera passagem, sendo um espaço de afeto que, certamente, requer intensidade e não apenas singelas horas com espaçamento quinzenal, como tradicionalmente visualizávamos no Poder Judiciário. (ROSA, 2019, p. 148).

Importante destacar que a convivência familiar não está adstrita à família nuclear, composta por pai, mãe e filhos: comporta a convivência dos avós e parentes, sustentada pela diversidade de arranjos familiares formatados em razão da diversidade cultural, social e econômica do nosso país. Como bem elucidam Josiane Veronese e Joana Ribeiro:

A concretização da Doutrina de Proteção Integral pelo Estatuto da Criança e do
Adolescente e por leis posteriores ao longo dos anos, reforçou os direitos
fundamentais das crianças e adolescentes, com as duas Leis de Convivência Familiar
e Comunitária e Adoção (Lei n. $12.010 / 2009$ e Lei n. 13.509/2017), que asseguram
que a criança e o adolescente permaneçam no seio de sua família e pelo Marco Legal
da Primeira Infância (Lei n. 13.257/2016), que reforçou o papel do Estado como
investidor da paternidade responsável, levando à compreensão da importância das
crianças conviverem com o pai e a mãe, também valorizando-se o convívio com os
avós e com a rede familiar. (RIBEIRO; VERONESE, 2020).

Assim, ainda que vivenciando momentos de restrições causados pela pandemia, é importante dar ênfase à integridade das relações e a convivência entre pais e filhos, netos e avós pois são muitas as benesses desse encontro geracional, tanto para os sujeitos que estão em formação como também para os que se encontram em processo de envelhecimento, como destacam Larissa Tenfen Silva e Ana Paula Antunes de Oliveira em artigo intitulado A convivência de avós idosos e netos no contexto da pandemia da COVID-19 no Brasil: 
A valorização da convivência familiar mediante a possibilidade das trocas
geracionais permite uma série de benefícios recíprocos, pois a troca de conhecimentos
e experiências entre gerações pode ser um referencial importante para aqueles que se
encontram em fase de desenvolvimento, incentivando a construção de uma cultura
solidária e de valorização. Assim, é importante proteger a integridade das relações
entre netos e avós já que muitos são os ganhos desse encontro geracional, tanto para
os sujeitos que estão em formação, como para os que se encontram em processo de
envelhecimento, havendo a possibilidade de promoção mútua dos laços de
solidariedade, afetividade e de ampliação da convivência familiar e social. Além de
possibilitar uma mudança na cultura das famílias em valorizar a inclusão dos mais
idosos. (SILVA; ANTUNES, 2020, p. 297).

A garantia da convivência familiar às crianças e adolescentes como direito fundamental, portanto, é dever que deve ser resguardado pelo Estado, pela sociedade e pelos próprios familiares, em especial aqueles mais próximos, detentores do poder familiar. A preservação dos laços de afeto que derivam da convivência é indispensável à formação das crianças e adolescentes, em todas as idades. Privar a criança ou adolescente da companhia de um familiar é lhe privar de ambiente de desenvolvimento e crescimento seguros, em um tempo que não volta mais. A infância e a adolescência têm data certa na vida de cada indivíduo, e o convívio impedido não pode mais ser recuperado.

\section{Os limites e as possibilidades do exercício do direito de convivência em tempos de pandemia}

O cumprimento da convivência no período da pandemia tem sido objeto de discussões jurídicas por todo o país, em especial pela doutrina e jurisprudência, incansáveis no debate do assunto. A situação pandêmica sem precedentes vivenciada exige compreensão e adaptabilidade de todos, não podendo ser utilizada como justificativa para perpetrar abusos, em cuidado especial com as crianças, que sob o pretexto de proteção do vírus estão sujeitas a atos até mais gravosos, como violências psicológicas, em especial alienação parental.

Passados quase quatro meses do reconhecimento da pandemia, já se atingiu certo grau de amadurecimento jurídico a respeito da convivência dos filhos com pais que residem em distintas casas, tendo sido produzidos diversos estudos doutrinários e proferidas decisões judiciais. $^{5}$ Não se discute que o distanciamento social e quarentena são medidas importantes para a contenção da doença, no entanto dentro do próprio distanciamento já se permite a formação de "bolhas sociais", ampliando o grupo de convivência familiar do isolamento,

\footnotetext{
${ }^{5}$ O IBDFAM - Instituto Brasileiro de Direito de Família - mantém atualizado banco de decisões judiciais proferidas relativas a situações ocorridas durante a pandemia, que pode ser consultado no site http://www.ibdfam.org.br/conteudo/covid19decisoes
} 
mantendo familiares em contato. Se a COVID tem consequências incontroversas à saúde física, e é preciso o distanciamento social, não se pode esquecer que o mesmo distanciamento social também tem consequências graves, entre elas a saúde mental e emocional dos envolvidos, e neste caso, das crianças. A diferença entre o remédio e o veneno é a dose.

Observando os países que mantiveram as medidas mais severas de distanciamento social - conhecido como lockdown - é possível se verificar que em todos havia a exceção do deslocamento para convivência com filhos, dada a importância da presença dos pais na formação e cuidado das crianças. Destaca Viviane Girardi:

Vale considerar que a pandemia não é motivo suficiente a inibir o contato entre pais e filhos e ou a suprimir o direito de convivência, tanto que países europeus severamente atingidos pelo COVID-19, a exemplo de Itália e França mantiveram entre as atividades permitidas para circulação das pessoas o exercício do direito de convivência. (GIRARDI, 2020, p. 234).

Esta convivência deve ser preferencialmente presencial, pois não há como se garantir a formação de laços e vínculos por meio telepresencial, ou seja, com ligações de áudio e vídeo. É importante o contato pessoal para tanto. Ainda, como já exposto, a convivência não se restringe a momentos de lazer ou descontração, mas a cuidados, responsabilidade, a participar da vida das crianças e adolescentes em seu cotidiano. Isto somente é possível por meio da convivência presencial, não podendo ser substituído ou compensado. A psicóloga Glicia Brazil escreveu a respeito no artigo intitulado Efeitos do convívio virtual para o vínculo de afeto dos vulneráveis:

Peço licença para concluir, desde já, que falas do tipo 'o tempo perdido com as crianças será compensado’ servem tão somente para amenizar a angústia que envolve a questão da convivência em tempos de crise, porque do ponto de vista técnico, a estimulação tátil, o cheiro, o calor da pele, o toque e as muitas formas de interação corporal entre seres humanos são superiores à experiência subjetiva de sentir-se cuidado e amado. [...] Levando esse conceito teórico para os processos judiciais, uma criança só consegue manter boa relação com o outro genitor e família extensa deste se o cuidador primário a estimule para ir ao encontro de outras pessoas de modo a permitir que a criança se sinta segura para retornar, sem que esse afastamento temporário gere no vulnerável a crença de punição ou rejeição, que são fantasias comuns apresentadas por filhos de pais separados em litígio, podendo a criança ficar dividida entre ter que escolher entre um dos lados da família, conflito conhecido como de lealdade, comum, transitório e que faz parte do divórcio. (BRAZIL, 2020, p. 244).

A manutenção de contatos por meios exclusivamente telepresenciais foi uma solução imediata na busca da manutenção dos vínculos entre familiares, ao mesmo tempo que cumpre com as medidas de distanciamento social. Esta solução seria aceitável se o período da pandemia não ultrapassasse um ou dois meses, período médio das férias escolares de verão, por exemplo. No entanto, a situação de emergência ocasionada pela pandemia já ultrapassa os quatro meses, e não há perspectiva de que esteja completamente resolvida até o final deste ano, ou seja, pode facilmente ultrapassar os dez meses. Desta forma, não se pode sustentar que é possível manter 
o contato entre pais e filhos, ou avós e netos, apenas pelos meios digitais. Em interessante estudo publicado pelas juristas Ana Carla Harmatiuk Matos e Lígia Ziggiotti de Oliveira, juntamente com a médica Letícia Ziggiotti de Oliveira, faz-se o destaque da importância da convivência presencial ${ }^{6}$ :

[...] a ocupação dos cuidados de crianças e adolescentes ultrapassa o diálogo virtual. A comunicação remota pode servir para a satisfação legítima da preocupação dos genitores com a prole, bem como para contornar a escassez afetiva completa decorrente da ausência de qualquer contato. Não se configura, porém, como medida capaz de compartilhar o efetivo exercício diário de cuidados representado pelo preparo de alimentos, higienização, atendimento aos medos, às dores e à agenda educacional de homeschooling atualmente intensa de algumas crianças e de adolescentes. [...] Como não há até o momento tratamento nem vacina que refletiriam na redução do número de internações hospitalares e no tempo previsto de circulação do patógeno, é possível que o novo Coronavírus esteja presente no nosso meio por um período prolongado. Deste modo, as medidas de prevenção individuais devem, ao menos até que a epidemia esteja encerrada ou controlada, tornar-se um novo modo de operação pessoal a longo prazo. (MATOS; OLIVEIRA; OLIVEIRA, 2020, p. 262).

Se a convivência familiar deve ser presencial, emerge a possibilidade de modificação dos ajustes ordinários de convivência, com a intenção de evitar deslocamentos desnecessários das crianças e adolescentes. Logo nas primeiras semanas de pandemia, foi sugerido pelo prof. João Ricardo Brandão Aguirre que a convivência entre pais e filhos durante a suspensão das aulas presenciais poderia ser feita seguindo o regime de férias, ideia surgida em debate posteriormente referenciado pelo Professor da USP, José Simão, publicado na página do $\operatorname{IBDFAM}^{7}$ :

Pode-se, ainda, seguir a sugestão de João Aguirre, nesse momento de suspensão de aulas presenciais e de ensino à distância. Permitir às crianças que residam 15 dias com o pai e 15 dias com a mãe, já que boa parte das pessoas se encontra em home office. Isso tem duas vantagens: a criança convive com pai e mãe e não fica afastada de nenhum deles por período longo, o deslocamento se dará duas vezes por mês apenas (o que o confinamento permite), e ajuda pai e mãe a produzirem em home office, pois terão 15 dias do mês sem a preocupação com os cuidados que os filhos exigem. (SIMÃO, 2020, p. 6).

A ideia da aplicabilidade do regime de convivência de férias para as crianças enquanto houver a suspensão das atividades presenciais ganhou força pela doutrina, sendo reforçada a mesma conclusão de estudo realizado pelo MPSC, no qual consta expressamente que os pais devem conviver com seus filhos, inclusive com a possibilidade de tal visita ser em períodos de

\footnotetext{
6 Construção de convivência parental adequada em tempos de COVID-19: Entre demandas jurídicas e recomendações médicas

${ }^{7} \mathrm{http}$ ://www.ibdfam.org.br/artigos/1405/Direito+de+fam\%C3\%ADlia+em+tempos + de+pandemia $\% 3 \mathrm{~A}+$ hora + de +escolhas+trágicas.+Uma+reflexão+de+7+de+abril +de+2020:
} 
tempo superior, para evitar deslocamentos ${ }^{8}$ No mesmo sentido, as conclusões trazidas em artigo de Josiane Veronese e Joana Ribeiro:

O lar referencial continua o mesmo, contudo, diante da ausência de aulas presenciais e da manutenção da educação à distância, para os casos em que a convivência nas férias foi dividida e a criança se sente bem em períodos de separação de um e outro, poderão os pais manter a convivência no sistema de férias, ficando 10 a 15 dias com cada um, cientes de que no dia da troca nenhum dos pais esteja infectado ou com o risco de ter sido. Em casos de insegurança de algum dos pais quanto aos cuidados pelo outro, podem ser acrescentadas cláusulas que garantam a manutenção do biorritmo da criança, ligadas à alimentação, ao horário do sono, ao horário de estudo, responsabilidades com vacinas e consultas médicas e outros pormenores que, previstos, podem dar maior tranquilidade na manutenção da rotina da criança e do adolescente, apesar da alteração da convivência. (RIBEIRO; VERONESE, 2020).

Esta opção por acompanhar o período de férias é defendida pelas professoras Fernanda

Tartuce e Simoni Tassinari, uma vez que esta medida atinge a finalidade de equilibrar a proteção à criança em tempos pandêmicos, e garantir a convivência com ambos os pais.

Eventualmente, caso a caso, ajustes nos períodos de convivência podem vir a ser recomendados. Aplicar ao período de quarentena o regramento do período de férias soa adequado por garantir 'que a criança fique menos exposta a idas e vindas e, assim, esteja mais salvaguarda, garantido o convívio equilibrado e o cuidado conjunto’ $[\ldots]$

Há efeitos jurídicos previstos para o genitor que impõe alterações unilaterais e não autorizadas no regime de convivência. Dispõe o $\S 4^{\circ}$ do artigo 1.854 do Código Civil que 'a alteração não autorizada ou o descumprimento imotivado de cláusula de guarda compartilhada' tem como consequência a redução de prerrogativas atribuídas ao genitor que assim o fizer. Logo, afastar forçadamente um filho de um dos genitores é atitude que só pode acontecer de modo autorizado, devendo ocorrer quando a manutenção da convivência apresentar risco real à saúde da criança. (TARTUCE; TASSINARI, 2020, p. 167).

Por fim, após debates doutrinários, foi apresentado Projeto de Lei n 2947 de autoria da Senadora Soraya Thronicke ${ }^{9}$, construído conjuntamente com professores de todo o Brasil, que visa unificar o procedimento em todo país a respeito das relações familiares, tendo um artigo especialmente dedicado à convivência entre pais e filhos:

Da guarda e do regime de convivência

Art. 5o O regime de convivência de crianças e adolescentes, qualquer que seja a modalidade de guarda, fica mantido durante o período de quarentena ou isolamento social.

$\S 1$ o Na hipótese de suspensão das atividades escolares presenciais, a convivência poderá ocorrer tal como no período de ferias, ou com o agrupamento dos dias de convivência.

§ 20 Em circunstâncias absolutamente excepcionais e em atenção ao melhor interesse da criança, poderá haver a suspensão judicial ao regime presencial de convivência por prazo não superior a 30 (trinta) dias, prorrogáveis por mais 30 (trinta), garantindo-se o convívio telepresencial por meio virtual e, em sua ausência, por telefone.

\footnotetext{
${ }^{8}$ https:/www.mpsc.mp.br/noticias/mesmo-com-isolamento-social-filhos-tem-direito-ao-convivio-com-ospais-separados

9 (https://www25.senado.leg.br/web/atividade/materias/-/materia/142151)
} 
Na justificativa do projeto a explicação de que se busca preservar a convivência entre pais e filhos - ambos os pais.

As medidas de isolamento social e quarentena, por sua vez, têm imposto desafios aos
pais separados, especialmente para aqueles que compartilham a guarda de seus filhos.
No contexto atípico da pandemia, nenhum acordo pretérito ou decisão judicial sobre
guarda chegou a prever a adaptação dos períodos de convivência à nova realidade.
Nesses casos, o regime de convivência dos pais com os filhos menores, nas hipóteses
de divorcio ou dissolução de união estável, normalmente foi pautado, sem clausulas
de exceção, pela alternância entre as residências, o que implica o deslocamento regular
de crianças e adolescentes, em contrariedade as normas restritivas de circulação e de
contato social em tempos de pandemia.
Em busca de uma solução que melhor atenda ao superior interesse da criança e do
adolescente, sem descurar dos interesses dos pais, estamos sugerindo uma regra de
transição compatível com o sistema que atualmente regula o exercício do poder
familiar, da guarda e da convivência dos filhos com seus genitores, que prioriza o
compartilhamento de responsabilidades e convivência equilibrada.

Ainda, destaca a justificativa do projeto que a suspensão da convivência deve ser exceção, e não a regra, e que mesmo quando ocorra não deve ser maior do que 30 dias, sob pena de impor às crianças restrições por demais severas.

\begin{abstract}
A redação ora proposta prioriza a manutenção da convivência já estabelecida para o caso concreto, possibilitando a aplicação do regime previsto para o período de ferias, bem como o agrupamento de dias, tratando como exceção a suspensão da convivência, para a qual prevê limites. Com efeito, ao tratar a suspensão da convivência como hipótese excepcional e manter como regra o antes definido, a proposta desestimula novos conflitos e o abuso do direito no exercício da autoridade parental.

A redação sugerida visa a organizar de forma gradativa as possibilidades para o exercício da convivência durante o período de isolamento social, prestigiar sua manutenção e evitar novos conflitos. Além disso, não prejudica uma nova composição temporária entre os pais, nem a atuação do julgador que, no caso concreto, aplicará o que melhor atender aos interesses dos envolvidos, sobretudo da criança e do adolescente.
\end{abstract}

Esta limitação temporal visa justamente a reflexão nas situações em que um dos pais está na linha de frente, exercendo atividades essenciais que não podem ser interrompidas durante a pandemia, como profissionais da saúde, ou trabalhadores de supermercados, farmácias, policiais, entre outros. Se por um lado estas atividades acarretam maior exposição individual ao risco da contaminação, por outro não se pode perder de vista que as pessoas que as exercem o fazem em prol da coletividade. A continuidade no exercício das atividades profissionais essenciais tem por consequência a intensificação do stress e desgastes emocionais não apenas aos trabalhadores, mas a todos os seus familiares. Não parece razoável, portanto, a solução de suspender o convívio pelo simples exercício da atividade sem qualquer limitação de tempo, sob pena de exigir destes profissionais e de suas famílias mais um sacrifício individual. Ademais, os casos em que o sistema de justiça necessita intervir para regulamentar ou suspender a convivência de filhos com pais que estejam exercendo atividades essenciais são os casos em que o núcleo parental se divide em mais de uma casa. As demandas são provocadas pelo pai ou 
mãe que não exercem a atividade essencial e não residem no mesmo lar, intensificando as dificuldades já havidas no relacionamento entre estes pais, e privando o filho de uma convivência que teria caso todos residissem na mesma casa. Não existem regras ou orientações sanitárias que impeçam os profissionais da saúde, por exemplo, de retornar ao seu lar ou de conviver com seus familiares.

No momento em que estamos atualmente, a suspensão da visitação deve ocorrer estritamente nos casos de suspeita do contágio, ou efetiva contaminação, ou ainda, caso um dos pais se recuse a obedecer às normas sanitárias de prevenção da contaminação. Ainda assim, tal suspensão deve ocorrer pelo prazo máximo de um mês, devendo ser revista periodicamente, a fim de que se preserve o convívio familiar.

Se a convivência entre pais e filhos deve ser mantida presencialmente, sendo a suspensão uma exceção, resta o questionamento a respeito da manutenção do convívio da criança com demais familiares, em especial com os avós, que em boa parte se encontram em grupo de risco, por serem maiores de 60 anos. A respeito deste assunto, remete-se à leitura do texto sobre a convivência dos avós durante a pandemia, escrito por Larissa Tenfen Silva e Ana Paula de Oliveira Antunes. Destaca-se, no entanto, a conclusão das autoras pela importância da manutenção do direito de convivência, que não deverá ser suspenso, mas em determinadas situações, quando haja risco à saúde e à vida das crianças e dos idosos, seja limitado e graduado este direito, com base na substituição da convivência presencial por convivência digital. A contrário sensu, quando houver possibilidade da manutenção segura das visitas presenciais, ainda que readequadas a nova situação, deve ser estimulada e efetivada. (SILVA; ANTUNES, 2020)

Desta forma, a manutenção do convívio familiar entre avós idosos e seus netos concretiza, a um só termo, a proteção e o melhor interesse dos indivíduos envolvidos, contribuindo para a promoção de uma cultura de valorização dos encontros geracionais e de um envelhecimento digno, ativo, saudável, inclusivo e autônomo da pessoa idosa, ainda que exercido em tempos de pandemia e isolamento. (SILVA; ANTUNES, 2020).

\section{A Fraternidade como vetor principiológico para relações familiares durante e após a pandemia}

A convivência entre familiares ganha novos desafios e contornos frente a pandemia da COVID-19. A tutela da promoção e proteção da convivência familiar de outros tempos, passa a ser agora foco de limitação, uma vez que diante da doença da COVID-19 é a própria 
convivência que pode afetar outros direitos relacionados aos membros da família, como a vida e a saúde.

Todavia, a proteção da saúde e da vida deve ser equacionada com o direito fundamental a convivência familiar. $\mathrm{O}$ direito a convivência familiar é uma conquista que visa a proteção especial aos membros vulneráveis das famílias, como crianças, adolescentes e idosos. Assim, o desafio atual é definir formas de compatibilizar tais direitos ainda que haja necessidade de novos arranjos na forma do seu exercício. A restrição de um não deve anular, em grau máximo, o outro.

A situação requer uma dose excessiva de civilidade e bom senso, de alteridade e empatia para que se encontre uma solução razoável e amistosa, voltada sempre à proteção dos filhos e dos idosos, preferencialmente. Mas como exigir bom senso de indíviduos submetidos aos mais variados fatores de stress pessoal, social e coletivo? Urge, portanto, mais do que nunca, a promoção do princípio da fraternidade, que embora pareça não ter ocupado a expressividade nos documentos jurídicos que a igualdade e liberdade (VERONESE, 2011, p. 126) até o momento, pode trazer um vetor de direcionamento nesta crise social.

A pandemia exige da sociedade, da família e dos seus indivíduos uma unidade e cooperação para enfrentamento das dificuldades emocionais, financeiras, políticas e de saúde pública decorrentes. Em épocas em que os indivíduos encontram-se esgotados física e emocionalmente, sob constante stress nos mais variados setores existenciais, a família deve resgatar o seu papel de núcleo de proteção e amparo aos indivíduos, o que somente será possível com uma importante mudança de paradigma, com a compreensão de que é necessária a unidade dos seus membros para a promoção da paz. Sobre a importância da mudança para a cultura de paz, destaca-se que:

Não se trata tão somente, ainda que bem vinda, da mediação, da justiça restaurativa, da conciliação... modelos alternativos de resolução de conflitos, mas faz-se necessário que nos lancemos numa cultura de paz, não se trata de obstar o ódio e o contra-ódio, pois a paz é a que precisa clarificar todas as relações humanas, de modo que não basta um discurso de contra-ódio, mas um efetivo compromisso com a paz. (VERONESE, 2019, p. 15).

A fraternidade entra como elemento fundamental de equilíbrio, pois resgata o sentido de irmandande, harmonia, paz e concórdia como um bem jurídico a ser atingido.

Em seu sentido etimológico a categoria fraternidade, do latim fraternitate, nos confere a ideia de irmandade, do amor ao próximo, da harmonia, paz, concórdia, portanto, quais serão os efeitos da efetivação deste princípio? Tradicionalmente a solidariedade é reconhecida como categoria jurídica na grande maioria dos países, porém a fraternidade representa um avanço doutrinário, pois vai além da concepção de sermos responsáveis uns pelos outros, mas sentirmos, efetivamente, a humanidade num todo como uma grande e única família que torna a todos irmãos. (VERONESE, 2011, p. 126). 
O momento de crise pode ser um instrumento para a mudança na cultura do conflito para a cultura da paz, gerando benefícios mútuos a todos os membros familiares. Passados os primeiros meses da pandemia, a doutrina, jurisprudência, e até projetos legislativos já reconheceram meios de compatibilizar a convivência familiar com o distanciamento social por meio de um regime especial, adaptável ao momento de isolamento social vivenciando em razão do surgimento da COVID-19.

Ajustes nos períodos de convivência e modificações de guarda, podem ser recomendados, como também cabe em determinados casos, a suspensão do direito do regime de convivência familiar ou parental, havendo necessidade de análise minuciosa e cautelosa, para que a solução encontrada seja coerente e encontre amparo judicial de forma a equilibrar e preservar o juízo de ponderação entre a garantia da convivência comunitária e familiar e de outro, a proteção a vida e a saúde da criança, adolescente e idosos.

A resistência em ajustar a convivência familiar pode ainda trazer consequências mais danosas às crianças e adolescentes no período de pandemia, em que a proteção e o amparo familiar se faz mais importante, já que as crianças estão privadas de convívio social, contatos presenciais com amigos, idas ao colégio, práticas de esportes e as mais diversas atividades que demandam o contato social, reduzido pelo imposto distanciamento. Como destaca Conrado Paulino da Rosa "sob a ótica da Doutrina da Proteção Integral, privar uma criança e adolescente da sadia convivência com seus ascendentes é, por certo, dispensar tratamento negligente, desumano e cruel [...]”. (ROSA, 2019, p. 143).

A situação pandêmica vivenciada já está sendo identificada pela doutrina como causadora e ampliadora da alienação parental, infelizmente. Como destacam as autoras Líbera Copetti de Moura Maici Barboza dos Santos Colombo:

O genitor alienador, sob o argumento de 'proteger' ou 'zelar' pelo bem estar da criança, oportuniza-se de tais situações fáticas, a fim de impedir o convívio, em especial naquelas situações de profunda beligerância já instalada. A alegação da necessidade de isolamento social, per si, não pode servir de instrumento de eventual suspensão arbitrária do regime de convivência com um de seus pais ou demais entes familiares, diante da própria natureza Constitucional do instituto, caracterizando por certo, qualquer afastamento imotivado como ato de alienação parental. Por sua vez, decisões que generalizam a suspensão do convívio, podem concretamente, servir de munição para que genitores pratiquem ou continuem praticando abusos em detrimento do direito de crianças e adolescentes, sujeitando-as a violência moral e psicológica, fazendo-se indispensável neste turno, estimular a convivência como regra geral e abstrata. Pais não visitam filhos. Pais convivem e exercem funções parentais, e quando inexiste coabitação devem, segundo a legislação pátria, exercer de forma conjunta e compartilhada os cuidados em relação a prole. Eventual medida de restrição de convivência deve ser analisada sob o enfoque da excepcionalidade e singularidade, sob pena de perpetração de abusos e incentivo à oportunismos. (MOURA; COLOMBO, 2020, p. 209-210). 
No mesmo sentido, destacam Renata Vilela Multedo e Diana Poppe, “ causa estranheza que as regras do jogo mudem em razão desse evento inesperado, pois [...] era de se esperar a parceria dos genitores para seguirem cuidando de seus filhos com responsabilidade [...] ajudando-se mutuamente". E continuam:

Esses combinados poderiam ocorrer informalmente entre cada família, ou mesmo
através de novos acertos extrajudiciais e provisórios, da forma mais simples possível,
sendo certo que, como se verá mais adiante, há no mercado uma gama de profissionais
experientes e capacitados para orientar e ajudar os pais a se reorganizarem em prol
das crianças, evitando-se o poder judiciário, que necessariamente tira a autoria dos
genitores na condução da vida dos menores. Porém, a questão sanitária abre também
caminho para novas desqualificações mútuas e questionamentos sobre quem cuidaria
melhor dos filhos nesse cenário, acirrando-se a disputa pelo poder absoluto atribuído
à autoridade. (MULTEDO; POPPE, 2020, p. 218).

É justamente neste ponto que a fraternidade pode afirmar-se como vetor princípiológico, promovendo a unidade entre os membros da família, superando a cultura individualista e de disputas. Desta forma, possível garantir a preservação dos laços familiares e afetivos, dos vínculos.

[...] a fraternidade, alvo deste estudo, é a que funda-se à unidade e, definitivamente, de forma resoluta, voltou as costas à dominação do poder e operou uma mudança decisiva: não mais pretende a luta fraticida, por excesso de egoísmo e individualismo; de igual forma abomina a dimensão conflituosa que por vezes a política instala e, por iguais razoes, não mais pretende o caráter inconciliável entre a liberdade, a igualdade e ela própria, e passa a dar ênfase ao que realmente importa: uma relacionalidade portadora de vínculos; uma relacionalidade comprometida com a gratidão. (ROSSETTO; VERONESE, 2017, p. 18).

Ainda que se compreenda os temores dos tempos vivenciados, é possível extrair algumas conclusões jurídicas, trazendo segurança jurídica as partes. Primeiramente, conclui-se que as restrições de deslocamento social decorrentes da pandemia do COVID-19 não podem servir de fundamento para afastamento entre pais e filhos, ou até mesmo entre outros familiares, devendo ser mantido e estimulado o convívio preferencialmente presencial, resguardando as normas sanitárias vigentes, ou ao menos telepresenciais, como opção secundária. Como decorrência desta conclusão, a suspensão ou limitação desta convivência deve restringir-se aos casos em que há contaminação de um dos envolvidos, ou suspeita.

$\mathrm{O}$ fato de um dos familiares exercer atividades profissionais essenciais que o exponham a maior risco de contaminação, ou o fato de um dos membros da família serem considerados grupo de risco pela idade ou condição de saúde, não pode fundamentar o total afastamento durante a pandemia, devendo ser preservado o contato familiar com as adequadas medidas de prevenção.

Sendo, portanto, possível, e recomendável a convivência familiar, a fraternidade pode atuar como vetor princiológico, fazendo com que os membros de uma família modifiquem a 
cultura do litigio, evitando judicializar tais questões, e promovendo a busca pela harmonização e paz, promovendo a função de proteção da família aos seus membros.

\section{REFERÊNCIAS}

BRAZIL, G. Efeitos do convívio virtual para o vínculo de afeto dos vulneráveis. In: NEVARES, A. L. M.; XAVIER, M. P.; MARZAGÃO, S. Coronavírus: impactos no Direito de Família e Sucessões. Indaiatuba: Editora Foco, 2020.

GIRARDI, V. Isolamento Social e o impacto sobre as mulheres e sobre o direito de convivência. In: NEVARES, A. L. M.; XAVIER, M. P.; MARZAGÃO, S. Coronavírus: impactos sobre o Direito de Família e Sucessões. Indaiatuba: Editora Foco, 2020.

MATOS, A. C. H.; OLIVEIRA, L. Z. D.; OLIVEIRA, L. Z. D. Construção de convivencia parental adequada em tempos de COVID-19: entre demandas jurídicas e recomendações médicas. In: NEVARES, A. L. M.; XAVIER, M. P.; MARZAGÃO, S. Coronavírus: impactos no Direito de Família e Sucessões. Indaiatuba: Editora Foco, 2020.

MOURA, L. C. D.; COLOMBO, M. B. D. S. Exercício do direito de convivência familiar em situações extremas: princípio do melhor interesse da criança e colisão de direitos fundamentais. In: NEVARES, A. L. M.; XAVIER, M. P.; MARZAGÃO, S. Coronavírus: impactos no Direito de Família e Sucessões. Indaiatuba: Editora Foco, 2020.

MULTEDO, R. V.; POPPE, D. Os limites da intervençao do Estado na responsabilidade parental em tempos de pandemia. In: NEVARES, A. L. M.; XAVIER, M. P.; MARZAGÃO, S. Coronavírus: impactos no Direito de Família e Sucessões. Indaiatuba: Editora Foco, 2020.

NAHAS, L. F.; FONTANELLA, P. A realização de casamentos no período de pandemia. In: NEVARES, A. L. M.; XAVIER, M. P.; MARZAGÃO, S. F. Coronavírus: impactos no Direito de Família e Sucessões. Indaiatuba: Editora Foco, 2020.

RIBEIRO, J.; VERONESE, J. R. P. A convivência familiar e a guarda compartilhada em tempos de pandemia covid-19. Disponível em: https://emporiododireito.com.br/leitura/aconvivencia-familiar-e-a-guarda-compartilhada-em-tempos-de-pandemia-covid19\#.XrRZ0wcYkng.whatsapp, 7 maio 2020.

ROSA, C. P. D. Do visitar ao "com viver": um novo olhar ao tempo dos filhos com cada um de seus genitores após as dissoluções afetivas. In: VERONESE, J. R. P.; SILVA, R. L. D. A Criança e seus Direitos: entre violações e desafios [recurso eletrônico]. Porto Alegre: Editora $\mathrm{Fi}, 2019$.

ROSSETTO, G. M. D. F.; VERONESE, J. R. P. Fraternidade e Unidade: paradigmas ao pensamento contemporâneo. In: VERONESE, J. R. P.; OLIVEIRA, O. M. B. A. D. Direito, Justiça e Fraternidade. Rio de Janeiro: Lumen Iuris, 2017.

SANCHES, H. C. C.; VERONESE, J. R. P. A Proteçao Integral e o Direito Fundamental de Crianças e Adolescentes à Convivência Familiar. In: VERONESE, J. R. P. Direito da

Criança e Adolescente. Rio de Janeiro: Lumen Iuris, 2017. 
SILVA, L. T.; ANTUNES, A. P. D. O. A convivencia de avós idosos e netos no contexto da pandemia da COVID-19 no Brasil. In: NEVARES, A. L. M.; XAVIER, L. P.; MARZAGÃO, S. F. Coronavírus: impactos no Direito de Família e Sucessões. Indaiatuba: Editora Foco, 2020.

SIMÃO, J. F. Direito de Família em tempos de pandemia: hora de escolhas trágicas. Uma reflexão de 7 de abril de 2020. In: NEVARES, A. L. M.; XAVIER, M. P.; MARZAGÃO, S. Coronavírus: impactos no Direito de Família e Sucessões. Indaiatuba: Editora Foco, 2020.

TARTUCE, F.; TASSINARI, S. Exigências de maior responsabildiade parental e ajustes sobre convivência familiar no contexto da pandemia. In: NEVARES, A. L. M.; XAVIER, M. C.; MARZAGÃO, S. Coronavírus: impactos no Direito de Família e Sucessões. Indaiatuba: Editora Foco, 2020.

VARGAS, H. L. O Direito à Convivência Familiar e o Isolamento Social Imposto pela Pandemia de COVID-19. In: BAHIA, S. J. C. Direitos e deveres fundamentais em tempos de coronavírus. São Paulo: Editora IASP, v. 2, 2020.

VERONESE, J. R. P. A academia e a fraternidade: um novo paradigma na fomação dos operadores do Direito. In: VERONESE, J. R. P.; OLIVEIRA, O. M. B. A. D. Direitos na Pós-modernidade: a fraternidade em questão. Florianópolis: Fundação Boiteux, 2011.

VERONESE, J. R. P. Convenção sobre os direitos da Criança 30 anos - sua incidência no Estatuto da Criança e do Adolescente. Salvador: JusPodivm, 2019.

VERONESE, J. R. P. O direito e o tempo na perspectiva da construção do ser criança. In: VERONESE, J. R. P.; SILVA, R. L. D. A Criança e seus Direitos: entre violações e desafios [recurso eletrônico]. Porto Alegre: Editora Fi, 2019. 